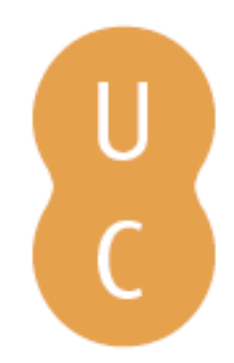

\title{
pompalina
}

\section{Embaucadores y falsos adivinos en Oráculos de la Pitia 407 B-C}

Autor(es): $\quad$ San Cristóbal, Ana Isabel Jiménez

Publicado por: Centro de Estudos Clássicos e Humanísticos; Imprensa da Universidade

URL

persistente: URI:http://hdl.handle.net/10316.2/31668

DOI: $\quad$ DOI:http://dx.doi.org/10.14195/978-989-8281-53-1_9

Accessed : $\quad$ 26-Apr-2023 14:03:25

A navegação consulta e descarregamento dos títulos inseridos nas Bibliotecas Digitais UC Digitalis, UC Pombalina e UC Impactum, pressupõem a aceitação plena e sem reservas dos Termos e Condições de Uso destas Bibliotecas Digitais, disponíveis em https://digitalis.uc.pt/pt-pt/termos.

Conforme exposto nos referidos Termos e Condições de Uso, o descarregamento de títulos de acesso restrito requer uma licença válida de autorização devendo o utilizador aceder ao(s) documento(s) a partir de um endereço de IP da instituição detentora da supramencionada licença.

Ao utilizador é apenas permitido o descarregamento para uso pessoal, pelo que o emprego do(s) título(s) descarregado(s) para outro fim, designadamente comercial, carece de autorização do respetivo autor ou editor da obra.

Na medida em que todas as obras da UC Digitalis se encontram protegidas pelo Código do Direito de Autor e Direitos Conexos e demais legislação aplicável, toda a cópia, parcial ou total, deste documento, nos casos em que é legalmente admitida, deverá conter ou fazer-se acompanhar por este aviso.

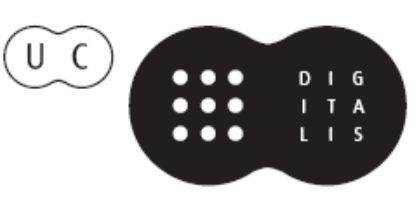




\section{Tychè et Pronoia}

\section{La marche du monde selon Plutarque}

Françoise Frazier et Delfim F. Leão (eds.)

IMPRENSA DA UNIVERSIDADE DE COIMBRA
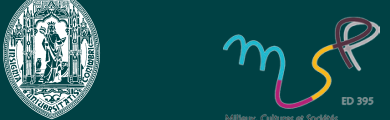


\section{Embaucadores y Falsos Adivinos \\ en ORÁCULOS DE LA PITLA $407 \mathrm{~B}-\mathrm{C}^{1}$}

Ana Isabel Jiménez San Cristóbal
Universidad Complutense de Madrid

\section{Resumen}

En Los oráculos de la Pitia (407B-C) Plutarco cuestiona la actuación de quienes intervienen sobre las respuestas oraculares para plegarlas a su interés personal porque minan la credibilidad de la mántica y la labor de los verdaderos profesionales del santuario délfico. Plutarco menciona la vinculación con el oráculo de hombres con dotes poéticas que versificaban las respuestas oraculares, de cresmólogos y de oficiantes de cultos orientales. El propósito de la comunicación es analizar quiénes eran esos personajes y las prácticas que ejercían para tratar de determinar su responsabilidad en la decadencia de la mántica.

\section{Introducción}

En el diálogo Los oráculos de la Pitia Plutarco aborda, entre otras cuestiones, la escasez de respuestas oraculares dictadas en verso en su tiempo y se pregunta si este hecho puede suponer un descrédito para el santuario ${ }^{2}$. Plutarco, sacerdote de Delfos durante más de veinte años, trata de salvar la credibilidad de los oráculos argumentado que la mayor parte de las respuestas antiguas también eran dictadas en prosa y que, en cualquier caso, el dios las impulsa, pero no las redacta ${ }^{3}$. Entre las causas de la preeminencia de la prosa en su tiempo Plutarco cita la falta de talentos dotados para la poesía, la situación política contemporánea, que había provocado que las preguntas al oráculo fuesen sencillas y se hiciese innecesario el recurso a la ambigüedad del verso, pero, sobre todo, la actuación de quienes intervenían de un modo u otro sobre las respuestas oraculares para plegarlas a su interés personal. Plutarco señala a personajes no ligados al templo como causantes de haber minado la credibilidad de la mántica y haber empañado la labor de los profesionales del santuario.

El propósito de este trabajo es tratar de determinar quiénes eran esos personajes y qué prácticas ejercían.

${ }^{1}$ Este trabajo forma parte del Proyecto de Investigación Consolider C "Cosmogonía y escatología en las religiones del Mediterráneo oriental: semejanzas, diferencias, procesos", financiado por el MEC (HUM2006-09403).

${ }^{2} \mathrm{El}$ problema se plantea en el capítulo séptimo $(397 \mathrm{D})$ y se convierte en tema central en los catorce últimos (402B-409D). Aunque en la tradición ha prevalecido el título latino del catálogo de Lamprias De Pythiae oraculis, los manuscritos transmiten el título griego

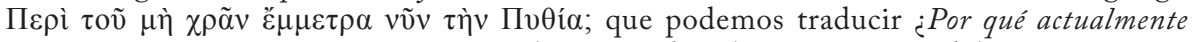
la Pitia no da sus respuestas en verso?, lo que indica la importancia del argumento en cuestión.

${ }^{3}$ Plu., Pyth. or. 403 A-F, 405 D-E. 


\section{Los Versificadores}

En la primera parte del pasaje que nos ocupa, Oráculos de la Pitia 407 B-C, Plutarco menciona la existencia de hombres con dotes poéticas que versificaban las respuestas oraculares a la manera de los rapsodos:

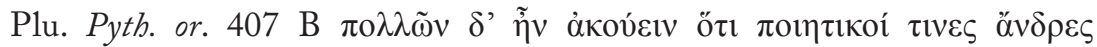

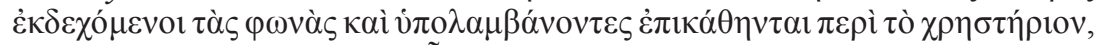

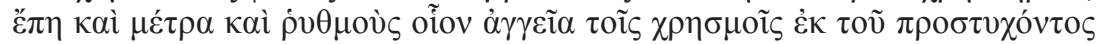
$\pi \varepsilon \rho 1 \pi \lambda \dot{\varepsilon} \kappa o v \tau \varepsilon \varsigma$.

Y a muchos se les podía oír decir que ciertos hombres con dotes poéticas estaban sentados juntos al oráculo recibiendo y recogiendo las sentencias y componían improvisadamente versos, metros y ritmos a modo de recipientes para los oráculos.

Es posible que se trate de los mismos personajes a los que en otro diálogo pítico se denomina $\pi \rho \circ \varphi \tilde{\eta} \tau \alpha$ y que formaban parte del clero del santuario délfico ${ }^{4}$. Su labor consistía en redactar las respuestas que transmitía la Pitia al consultante y versificarlas cuando era preciso, ya que en muchos casos la Pitia, mujer campesina y de escasa cultura, no podía darles forma hexamétrica ${ }^{5}$. Heródoto y Eurípides dan cuenta de la existencia de estos personajes, pertenecientes a la clase noble de Delfos, y Estrabón especifica que son servidores del templo dedicados a versificar las respuestas en prosa ${ }^{6}$. Parece que también en los oráculos de Claros y Dídima funcionarios similares se encargaban de la redacción de las respuestas en tiempos de Adriano ${ }^{7}$.

La presencia de los versificadores puede haber arrojado una sombra de duda sobre la autenticidad de los oráculos, que los delfios presentaban como producto genuino de la Pitia, y haber socavado su credibilidad. Plutarco, servidor él también del santuario, no cuestiona, sin embargo, la labor de estos

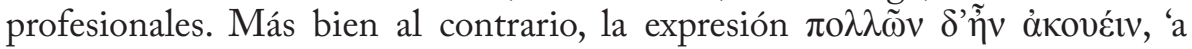
muchos se les podía oír decir', parece señalar el distanciamento voluntario del de Queronea respecto a quienes responsabilizaban a los versificadores de la decadencia del oráculo.

\section{Los Cresmólogos}

Plutarco parece querer distanciarse también de quienes achacan la pompa y el estilo trágico de los oráculos a los seguidores de Onomácrito, Pródico y Cinetón: $386 \mathrm{~B}$.

${ }^{4}$ Plu., Def. orac. 414 E, 438 B; véase también la denominación de icpeúc en $E$ ap. Delph.

${ }^{5}$ H. W. Parke, 1940; W. E. McLeod 1961; R. Flacelière, 1965, pp. 57-58; J. A. Fernández Delgado, 1991. S. Schröder, 1990, pp. 392-393, piensa, en cambio, que se trata de empresarios privados que habrían bajado al oráculo.

${ }^{6}$ Hdt., VIII 36; Eu., Io 413-416; Str., IX 3.5.

${ }^{7}$ H. W. Parke, 1940, 86, 1985, 220-221; J. Fontenrose, 1988, pp. 43, 78-80. 


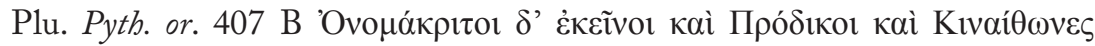

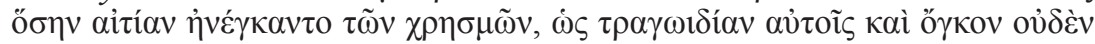

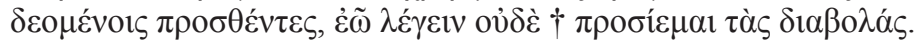

Cuánta responsabilidad en los oráculos tuvieron los Onomácritos, Pródicos y Cinetones, al añadirles estilo trágico y pompa sin que en absoluto los necesitaran, omito decirlo y no tolero las calumnias.

La mención de Onomácrito implica una referencia a los llamados $\chi \rho \eta \sigma \mu \mathrm{\lambda}$ ó $\gamma$ ol, compiladores de oráculos que trabajaban al margen de los grandes centros. Se dedicaban a comerciar con las respuestas y eran capaces de modificar un oráculo existente o forjar uno a medida para sus clientes. Estos cresmólogos, cuya edad de oro se sitúa durante la Guerra del Peloponeso, ponían en circulación oráculos anónimos o atribuidos a profetas legendarios, como Museo o Baquis, o a algún santuario famoso 8 .

Onomácrito vivió en la corte ateniense de los Pisistrátidas a finales del s. VI a. C. y se le atribuye la sistematización de los oráculos del legendario Museo, la participación en la redacción de los poemas homéricos y la compilación y composición de poemas atribuidos a Orfeo ${ }^{9}$. Según Heródoto $^{10}$, Onomácrito fue expulsado de Atenas por Hiparco cuando fue sorprendido en el flagrante delito de intercalar un oráculo propio en la recopilación de Museo. Marchó entonces a Susa donde puso su ciencia al servicio de Jerjes. La reconciliación con los Pisistrátidas debió de tener lugar cuando éstos, expulsados por los atenienses, recalaron también en la corte del rey persa.

Los Pisistrátidas eran adversarios políticos de los Alcmeónidas, quienes tenían gran influencia y control sobre el sacerdocio délfico. No parece verosímil la hipótesis de que Onomácrito, un cresmólogo filopisistrátida, hubiese realizado una recopilación de oráculos píticos y hubiese introducido en ella sus acostumbradas interpolaciones ${ }^{11}$. Es más probable que su actividad se limitase a recopilar e interpolar profecías en verso que los Pisistrátidas habrían depositado en el templo de la Acropólis para contraponerlas a los vaticinios provenientes del santuario hostil ${ }^{12}$. Es decir, Onomácrito y otros cresmólogos habrían contribuido al uso político de los oráculos en favor de determinadas ciudades, una manipulación que habría perjudicado la reputación de los oráculos y habría provocado el progresivo desafecto de los griegos por la adivinación ${ }^{13}$.

${ }^{8}$ Th., II 8; Ar., Au. 960, cf. M. P. Nilsson, 1954, pp. 218-219; R. Flacelière, 1965, pp. 67-72.

${ }_{9}^{9}$ Sobre el cual véase E. D’Agostino, 2007, pp. XI-XXIX; A. Bernabé, 2008, pp. 229-230;

M. Herrero, 2008, pp. 255, 261 n. 62, pp. 264, 277; R. Martínez Nieto, 2008, pp. 571-576.

${ }^{10}$ Hdt., VII 6.

${ }^{11}$ Véase, en cambio, F. Stoesse, 1972, cols. 304-305.

${ }^{12}$ Véase Hdt., V 62-63; V 90; VI 123, cf. E. D’Agostino, 2007, 58-59.

${ }^{13}$ R. Flacelière, 1965, 78. 
Más problemática resulta la mención de los otros dos individuos, Pródico y Cinetón ${ }^{14}$. Se ha propuesto identificar al primero con Pródico de Focea o con Pródico de Samos. El de Focea era conocido como autor de un poema épico titulado Miníada que trataba el castigo pagado por Támiris en el Hades ${ }^{15}$. A Pródico de Samos se le atribuía una obra órfica titulada Catábais de Orfeo ${ }^{16}$. Cinetón se ha vinculado con Cinetón de Esparta, un poeta genealógico y épico ${ }^{17}$. Carecemos de testimonios que relacionen a Pródico y Cinetón con los vaticinios oraculares, pero su evocación junto a Onomácrito podría justificarse por otros motivos. En primer lugar, ambos son autores épicos y la poesía oracular se inserta en el seno del epos tradicional en el que distintos autores pudieron tratar más de un género, como el épico y el mántico ${ }^{18}$. En segundo lugar, la temática escatológica de las obras de Pródico y Cinetón puede haber favorecido su vinculación con Onomácrito, ya que las catábasis ocupaban un lugar primordial entre los poemas órficos de los que la tradición le hacía compilador. Incluso, uno o dos versos de la Nekyia odiseica fueron atetizados y atribuidos a Onomácrito ${ }^{19}$. Desde el s. I d. C. su nombre se había convertido en comodín al que adscribir la literatura órfica o semejante cuya autencidad se pusiera en duda.

\section{Los Oficiantes de Cultos Orientales}

En la última parte del pasaje de Plutarco que nos ocupa, el de Queronea denuncia que lo que más descrédito causó al verso oracular fue la tropa embaucadora y feriante que vagabundea en torno al templo de la diosa Madre y de Serapis, recitando oráculos a esclavos y mujerzuelas:

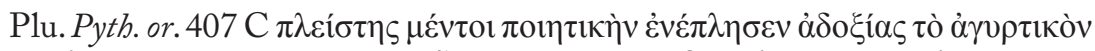

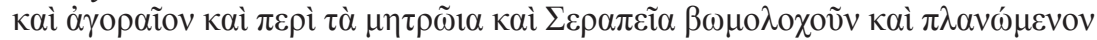

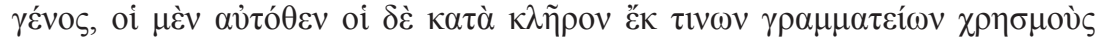

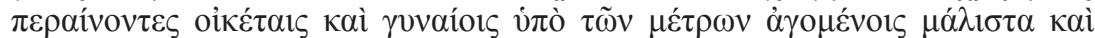

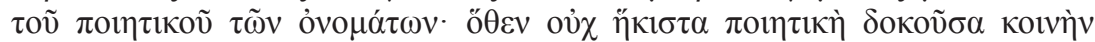

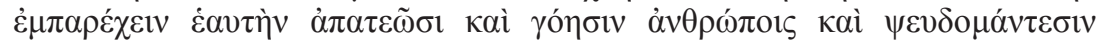

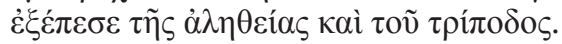

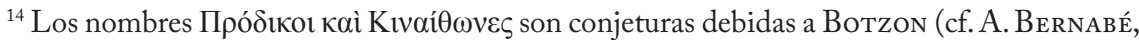
2005, p. 341 [OF 808], p. 530 [OF 1112]; E. D’Agostino, 2007, 5-6), no aceptadas por todos

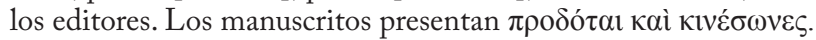

${ }^{15}$ A. Bernabé, 19962 , pp. 137-142. El tema es compatible con una catábasis.

${ }^{16}$ Clem. Al. Strom., 1.21.131.3, cf. A. Bernabé, 2005, p. 264 (OF 707), p. 469 (OF 1018 III). M. L. West, 1983, p. 10 n. 17 y A. Bernabé, 2005, p. 534 (OF 1124) sostienen que Clemente habría atribuido la catábasis a Heródico y que la lectura 'Pródico' de Samos sería una alteración de los copistas.

${ }^{17}$ A. Bernabé, 1996 , pp. $115-117$.

${ }^{18}$ Cf. J.A. Fernández Delgado, 1985, pp. 155-156 y n. 17.

${ }^{19} \mathrm{Sch}$. Hom. Od. XI 602 (525 Dindorf). No es claro si la atétesis afecta a 602 o 602-604. Los versos se ocupan de Heracles y son muy similares a otros pasajes de Hesíodo marcados con obelos en el Catálogo (Fr. 25 M.-W.) y la Teogonía (947-955). La razón de la atétesis tampoco está clara, cf. West ad loc. y M. Herrero, 2008, p. 264. 
Pero a la forma poética la colmó de pésima reputación la prole pedigüeña y demagoga que hace bufonadas en torno al culto de la Gran Madre y de Serapis y va de acá para allá recitando oráculos, unos de forma instantánea, otros sacándolos a suerte de ciertas tablillas, a esclavos y mujerzuelas que se dejan persuadir especialmente por los metros y la poesía de las palabras. De ahí precisamente que la forma poética, que parecía servir igualmente a embaucadores, hechiceros y falsos adivinos, haya quedado apartada de la verdad y del trípode.

Los cultos de origen oriental proliferaron en numerosas provincias del imperio romano, incluida la de Acaya, y gozaron de un gran favor sobre todo entre las clases populares ${ }^{20}$. El culto de Cíbele, la Gran Madre, diosa frigia que los griegos asimilaron a Rea, había penetrado en Grecia desde las Guerras Médicas y estuvo siempre caraceterizado por su dimensión mística y orgiástica $^{21}$. El culto de Serapis, una divinidad en la que se reconoce la fusión de Osiris y Apis ${ }^{22}$, fue implantado oficialmente en Alejandría durante el período helenístico en un intento de revestir de caracteres griegos a un dios de origen egipcio. En él confluyen los rasgos ctónicos de Osiris y Plutón, la fecundidad asociada a Apis y formas rituales propias de los misterios eleusinios ${ }^{23}$.

La intención de Plutarco parece haber sido denunciar el apropiamento indebido del oráculo por parte de ciertos sacerdotes de estos cultos y el menoscabo que ello produjo al prestigio de la institución. El de Queronea

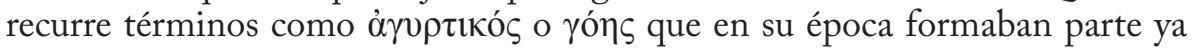
del vocabulario tradicional para referirse a oficiantes de ritos que conjugaban su labor con prácticas adivinatorias y oraculares.

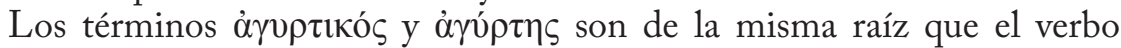
à $\gamma \varepsilon i ́ p \omega^{24}$, que significa 'mendigar o vivir de limosna'. Los vocablos puede aplicarse a distintos ámbitos ${ }^{25}$, pero los encontramos mayoritariamente referidos a personajes que se dedicaban a la adivinación y, en contexto religioso, a sacerdotes mendicantes que se ganaban la vida celebrando ritos asociados a la magia y a las prácticas adivinatorias ${ }^{26}$. Designan, por tanto, a quienes trataban de obtener beneficios materiales recurriendo por lo general a prácticas mágicas $\mathrm{y}$ adivinatorias, en principios ajenas a su profesión.

Adivinos ilustres son calificados de pedigüeños por querer sacar excesivo beneficio de su arte. Es el caso de Lampón en un texto de Lisipo y de Tiresias

${ }^{20}$ Sobre estos cultos, cf. J. Alvar, 2001; E. SAnzi, 2003, con bibliografía.

${ }^{21}$ E. Sanzi, 2003, pp. 38-40; J. Alvar, 2001, pp. 185-188.

${ }^{22}$ Clem. Al. Prot., 4.48.6.

${ }^{23}$ J. Alvar, 2001, pp. 58-67.

${ }^{24}$ Cf. P. Chantraine, 1968-1980 s. v. òyzípw; G. Lanata, 1967, pp. 41-42. 15.1.16.

${ }^{25}$ Como, por ejemplo, la medicina: Hp., Morb. Sacr. 1.10 (60 Grenseman); Luc., DDeor

${ }^{26} \mathrm{E} 1$ significado de mendigo, del que deriva lógicamente el de sacerdote mendicante, puede

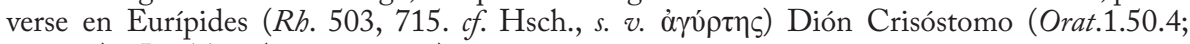
30.20.2) y Jámblico (Myst. 10.2.13). 
en otro de Sófocles ${ }^{27}$. En ocasiones la línea que dividía la frontera entre magia, adivinación y mendicidad debía de ser muy frágil, según denuncia Estrabón ${ }^{28}$.

El propio Plutarco parece considerar sinónimos los términos $\mu$ óv $\tau \imath \varsigma$ y

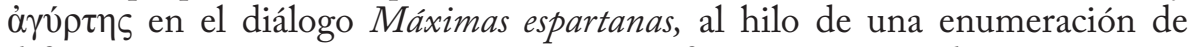
diferentes gremios, como comerciantes y sofistas, cuyo nexo de unión parece ser la obtención de ganancias ${ }^{29}$.

Además de los adivinos, reciben frecuentemente el calificativo de $\alpha \gamma u ́ \rho \tau \alpha \iota$ los sacerdotes de ciertos cultos. Por ejemplo, en un pasaje de la República, Platón dirige sus críticas contra 'sacerdotes mendicantes y adivinos', $\alpha \gamma u ́ \rho \tau \alpha 1$

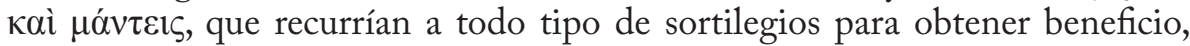
en especial, de los ricos ${ }^{30}$. En este y otros pasajes el filósofo traza una imagen despectiva de ciertos oficiantes de ritos órficos que, en su opinión, atacaban de lleno los postulados de la filosofía y amenazaban con romper el orden asegurado por la religión oficial ${ }^{31}$. El orfismo vinculaba la promesa de un destino mejor tras la muerte al cumplimiento de determinados ritos. No es de extrañar que junto a los sacerdotes que actuaban convencidos de la eficacia de esos ritos surgiesen falsarios dedicados a comerciar especulativamente con las promesas de salvación, aprovechándose de la buena fe de sus clientes. Platón critica esta degeneración, haciendo especial hincapié en el carácter heterogéneo y desordenado de las actividades de estos charlatanes (sacrificios y ritos de purificación y liberación, junto a ensalmos, encantamientos y actividades mágicas), no menos sorprendente e irracional que la oferta de potenciales beneficios: cancelación de culpas y delitos, acciones "teúrgicas" para constreñir a los dioses y provocar daños al enemigo, y liberación de las penas en el otro mundo. El rechazo que Platón podía sentir hacia estos cultos mistéricos se vería agudizado por el hecho de que los oficiantes, muy persuasivos y con gran poder de convocatoria ${ }^{32}$, pudieran influir sobre personajes poderosos, pertenecientes a las capas más altas del Estado y capaces de arruinar ciudades enteras ${ }^{33}$.

Siglos más tarde, Estrabón caracteriza a Orfeo como mago, mendigo, músico, adivino y oficiante de ritos orgiásticos, en una descripción en que la figura del cantor encarna rasgos propios de los orfeotelestas de la época ${ }^{34}$. La posición defensiva del historiador frente a la amenaza de las religiones mistéricas justifica la caracterización peyorativa de Orfeo, insistiendo en los

${ }^{27}$ Lysipp., VI (PCG 5, p. 620 K.-A.); S., OT 387-389.

${ }^{28}$ Str., X 3.23, cf. A. BernabÉ, 2002, pp. 62-63.

${ }^{29}$ Plu., Apophth. Lac. 226 D.

${ }^{30}$ P1., R. 364b-c (OF573 I), cf.A.I.JIMÉNEZ SAN CRISTóBAL, 2008,775-777, con bibliografía.

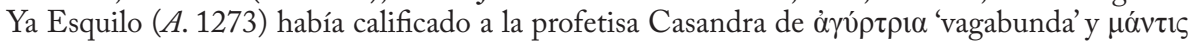
'adivina', reuniendo, por tanto, ambas facetas.

${ }^{31}$ Cf. et. P1., R. 364e, Lg. 909b.

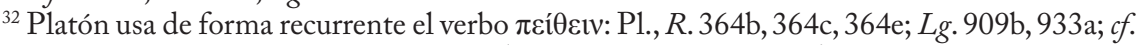

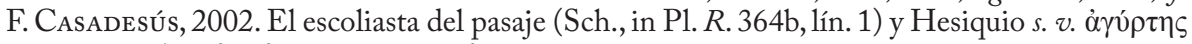
insisten en el poder de convocatoria de estos personajes.

${ }^{33}$ Pl., Lg. 908d, cf. F. Casadesús, 2002.

${ }^{34}$ Str., VII fr. 10a Radt (OF 554); A. Bernabé, 2002 considera que se trata de una lectura política del mito de Orfeo. 
aspectos que más lo acercan a los especuladores con fines ajenos a la religión.

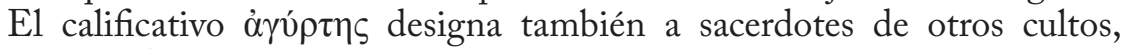
como el de Afrodita del que Plutarco ofrece un ejemplo en sus Historias griegas y romanas ${ }^{35}$. El vocablo denomina asimismo con relativa frecuencia a los oficiantes del culto de la Gran Madre. Ya en Aristóteles encontramos un término específico para referirse a los sacerdotes de Cíbele en tono despectivo, $\mu \eta \tau \rho \alpha \gamma \tilde{v} \rho \tau \alpha{ }^{36}$. Dioniso de Halicarnaso lo usa, pero ya sin ánimo peyorativo, para referirse a sacerdotes que celebran sus ritos en Roma, recorriendo las calles y pidiendo limosna, mientras entonan su cantos en honor de la Diosa

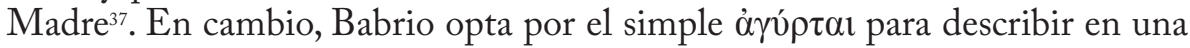
de sus Fábulas el comportamiento de los oficiantes de Cíbele, que vagan de un lado a otro recogiendo provisiones y celebrando ritos ${ }^{38}$. Por su parte, el lexicógrafo Hesiquio explica que los poetas cómicos denominaban ơ $\gamma u ́ \rho \tau \alpha \imath$ a los sacerdotes mendicantes de Cíbele precisamente por su relación con la magia y la realización de sacrificios ${ }^{39}$. En el pasaje de los Oráculos de la Pitia, Plutarco

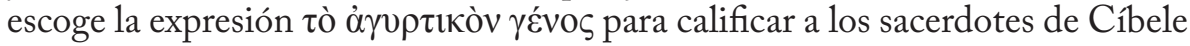
y Serapis. La elección este término, en lugar del más específico $\mu \eta \tau \rho \alpha \gamma u ́ \rho \tau \eta \varsigma$, quizá no se deba sólo a la inclusión de los oficiantes de Serapis. Nótese que en ninguno de los ejemplos citados de $\mu \eta \tau \rho \alpha \gamma u ́ \rho \tau \alpha l$ se precisa su relación con la mántica. En cambio, el vínculo es constante en los ejemplos del genérico à $\gamma \tilde{\rho} \tau \tau \eta$. Sin duda, el peso de la tradición platónica puede haber influido en la preferencia por este último.

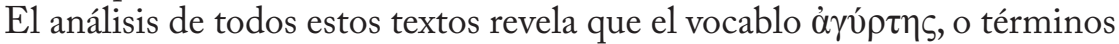
de su misma familia, señalan la degeneración que el lucro personal podía ocasionar entre adivinos y sacerdotes, unas veces porque corrompía a verdaderos profesionales, como Tiresias o Lampón, otras porque favorecía el intrusismo de falsos expertos en el oficio. En esta última categoría podrían incluirse ciertos sacerdotes de cultos orientales que en tiempos de Plutarco comerciaban con oráculos en verso.

Significativo es también el término yoń $\varepsilon \varsigma$ ‘hechiceros', con que Plutarco califica al final del pasaje a los oficiantes de cultos orientales. En principio, este nombre designa en griego a una figura compleja que aúna el éxtasis y el lamento ritual, la curación mediante ritos y las prácticas adivinatorias ${ }^{40}$, sentidos que lo convierten en término apropiado para calificar a los oficiantes de cultos mistéricos ${ }^{41}$.

${ }^{35}$ Plu., Aetia Romana et Graeca 303 C.

${ }^{36}$ Arist., $R$ h. 1405a 20. Plutarco también emplea el término para referirse en tono despectivo a Ptolomeo Filopátor: Plu., Cleom. 36. Sobre el vocablo, cf. F. Poland, i 932.

${ }^{37}$ D. H., II 19.

${ }^{38}$ Babr., 141-149.

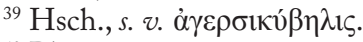

${ }^{40}$ Pl., Smp. 203a, Phlb. 44c; cf. W. Burkert, 1962; F. Graf, 1994, p. 35.

${ }^{41}$ Orfeo (Str., VII fr. 18), Pitágoras (D. L., VIII 36) y Empédocles (Gorg., A 3 D.-K., ap. D. L. VIII 58. 59) son llamados yớ $\varepsilon \varsigma$. Según E. R. Dodds, 1960, pp. 141-142, Empédocles representa al chamán que combina las funciones indiferenciadas de mago, naturalista, poeta y filósofo, predicador, sanador y consejero público. Cf. W. Burkert, 1962, p. 38 y n. 10, p. 48 y n. 
En un pasaje de las Leyes, Platón emplea el participio del denominativo

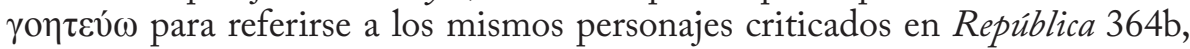

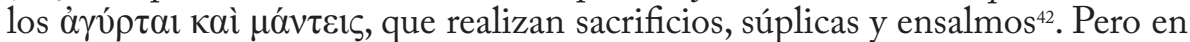
otros pasajes el vocablo tiene también el significado despectivo de 'estafador', 'mentiroso' o 'charlatán', en particular referido a los sofistas ${ }^{43}$.

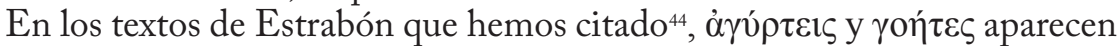
unidos en referencia a oficiantes que embaucan interesadamente a su clientela, lo mismo que en el texto de los Oráculos de la Pitia. Гóns encierra, por tanto, los valores de oficiante de ritos, hechicero, mago, adivino y timador. Todos ellos reaparecen posteriormente en Luciano. Así en Alejandro o el falso profeta, el de Samósata dirige su aguda crítica contra quienes se dedicaban a comerciar con el miedo y la superstición de los hombres vendiendo oráculos y remedios a supuestos males, emulando a los sacerdotes de ciertos cultos. ${ }^{45} \mathrm{~A}$ esa caterva pertenece el protagonista del diálogo, un truhán, medio sacerdote, medio milagrero-curandero y medio adivino. En Sobre la muerte de Peregrino Luciano ataca, en los mismos términos, a los magos y hechiceros que se aprovechaban de las circunstancias para hacerse ricos entre los cristianos, mientras que en $L a$ Asamblea de los dioses su crítica se centra en los charlatanes y timadores que se dedicaban a dar oráculos provocando el desprestigio de la sede délfica ${ }^{46}$. Las denuncias previas de Plutarco parecen no haber surgido efecto.

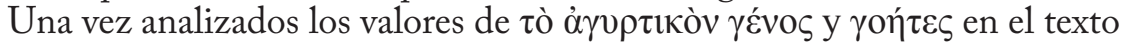
de Plutarco, podemos suponer que la denominación despectiva $\psi \varepsilon v \delta \delta \mu \alpha{ }^{2} v \tau \varepsilon 1 \varsigma$, 'falsos adivinos', que cierra el pasaje hace referencia a las actividades asociadas a este tipo de personajes, y no a la práctica de la cleromancia, es decir, la adivinación sacando al azar palabras escritas en ciertos guijarros ( $\kappa \lambda \tilde{\eta} \rho \circ \varsigma)$, que está bien atestiguada en relación al oráculo de Delfos y se supone anterior a la adivinación inspirada por el entusiasmo ${ }^{47}$. En cualquier caso, da la impresión de que, en cierta medida, Plutarco responsabiliza también de la decadencia del oráculo a la clientela que acude a estos embaucadores y falsos adivinos. La falta de juicio de mujerzuelas y esclavos habría propiciado un aumento del negocio y la consecuente proliferación de estos personajes. En este sentido, cabe destacar que en el diálogo Sobre la superstición Plutarco reprocha a los supersticiosos su

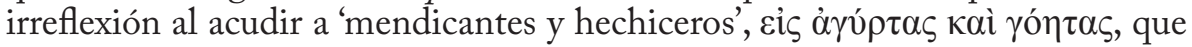
no son sino falsos profesionales ${ }^{48}$.

61; Ch. Riedweg, 1997, pp. 35, 38-41, 51 y n. 116.

${ }^{42}$ Pl., Lg. 909b (OF 573 IV).

${ }^{43}$ P1., Sph. 241b, Plt. 291c, 303c. Cf. Aeschin., III 137; D. XVIII 276, XIX 102, 109, XXIX

32. Sólo en tres pasajes parece no tener ese valor negativo: A., Ch. 822.; Gorg., 82 A 3 D.-K.; P1., Smp. 203.

${ }^{44}$ Str., X 3.23; VII fr. 10a Radt (OF 554).

${ }^{45}$ Luc., Alex. 1, 5, 6, 25, 60.

${ }^{46}$ Cf. Luc., Peregr. 13, Deor. Con. 12. En DMort. 10.2 ataca a Trofonio por sus hechizos

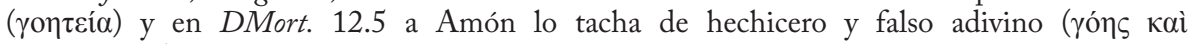
$\psi \varepsilon v \delta o ́ \mu \alpha v \tau \iota \varsigma)$.

${ }^{47}$ Cf. R. Flacelière, 1965, pp. 23-24, 41, 54-55; P. Amandry, 1950, 25ss.

${ }^{48}$ Plu., Superst. 166 A. 


\section{Conclusiones}

Llegados al final podemos extraer algunas conclusiones. Plutarco distingue diversos niveles de responsabilidad en la decadencia del oráculo. No cuestiona la labor de los versificadores, a los que se refiere en términos no peyorativos como

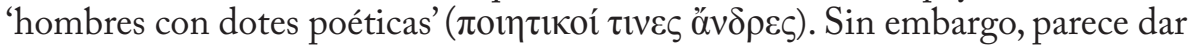
a entender que la forma poética ha podido ensombrecer la autenticidad de los oráculos, en principio presentados como productos genuinos de la Pitia. La poesía podía constutituir la puerta de entrada de falsos profetas. Algo similar pudo ocurrir con los cresmólogos, quienes, en principio, no tenían por qué ser causantes de la decadencia oracular. Ahora bien, la manipulación de las respuestas para obtener réditos políticos en ciertos casos pudo afectar a la reputación del oráculo y provocar el progresivo desafecto de los griegos por la adivinación. Finalmente, Plutarco señala como verdadero origen del descrédito de la mántica a falsos oficiantes de cultos orientales que traficaban con prácticas

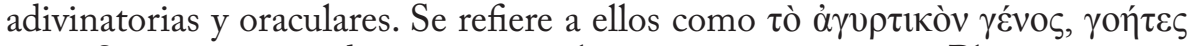
y $\psi \varepsilon v \delta o \mu \alpha ́ v \tau \varepsilon 1 \zeta$, usando una terminología que aparece ya en Platón y que se mantiene a lo largo de la tradición posterior para designar a 'falsos oficiantes' que con el pretexto de celebrar ritos pretendían simplemente ganar dinero. Del uso de dicha terminología se desprende que la intención de Plutarco no es tanto criticar estos cultos como desenmascarar a quienes en su nombre recurrían a la práctica y a la adivinación con fines exclusivamente lucrativos. 


\section{Bibliografía}

Alvar, J., Los misterios. Religiones "orientales" en el Imperio Romano, Barcelona, 2001 (= Romanising Oriental Gods. Myth, Salvation, and Ethics in the Cults of Cybele, Isis, and Mithras, Leiden-Boston, 2008).

Amandry, P., La mantique apollinienne à Delphes. Essai sur le fonctionnement de l'Oracle, Paris, 1950 (reimp. New York, 1975).

Bernabé, A., Poetae Epici Graeci. Testimonia et fragmenta, Pars. I, Stuttgardiae et Lipsiae, $1996^{2}$.

—, “Un 'resumen de historia del orfismo' en Strab. 7 fr. 18”, en J. F. GonzÁlez Castro \& J. L. Vidal (eds.), Actas del X Congreso Español de Estudios Clásicos, vol. III, Madrid, 2002, 59-66.

—,Poetae Epici Graeci. Testimonia et fragmenta, Pars. II, Orphicorum et Orphicis similium testimonia et fragmenta, fasc. II, Monachii et Lipsiae, 2005.

-, "Atribución a Orfeo de una tradición poética", en A. Bernabé \& F. Casadesús (eds.), Orfeo y la tradición órfica: un reencuentro, Madrid, 2008, 227-237.

Burkert, W. "ГОН $\Sigma$. Zum griechischen 'Schamanismus”, RhM, 105, 1962, 36-55.

Casadesús, F., "La crítica platónica de la magia”, en J. Peláez (ed.), El dios que hechiza y encanta. Magia y Astrología en el mundo clásico y helenistico, Madrid, 2002, 191-201.

D’Agostino, E., Onomacrito. Testimonianza e frammenti, Pisa-Roma, 2007.

Dodds, E. R., Los griegos y lo irracional, Madrid, 1960 (ed. or.: The Greeks and the Irrational, Berkeley-Los Angeles, 1951).

Fernández Delgado,J.A., "Poesía oral mántica en los oráculos de Delfos”, en J. L. Melena (ed.), Symbolae Ludovico Mitxelena septuagenario oblatae, Vitoria, 1985, 153-166.

-, "El testimonio de Plutarco y los modernos estudios sobre el oráculo de Delfos", en Homenaje a A. Holgado, Universidad de Extremadura, 1991, 57-72 (non vidi).

Flacelière, R., Adivinos y oráculos griegos, Buenos Aires, 1965 (ed. or.: Devins et oracles grecs, Paris, 1961).

Fontenrose, J., Apollo's Oracle, Cult, and Companions, Berkeley-Los AngelesLondon, 1988.

Graf, F., La magie dans l'antiquité Gréco-Romaine, Paris, 1994 (= Magic in the Ancient World, Cambridge, 1997). 
Herrero, M., “Tradición órfica y tradición homérica”, en A. Bernabé \& F. Casadesús (eds.), Orfeo y la tradición órfica: un reencuentro, Madrid, 2008, 247-278.

Jiménez San Cristóbal, A. I., "Los orfeotelestas y la vida órfica”, en A. Bernabé \& F. Casadesús (eds.), Orfeo y la tradición órfica: un reencuentro, Madrid, 2008, 771-799.

Lanata, G., Medicina magica e religione popolare in Grecia fino all'età di Ippocrate, Roma, 1967.

Martínez Nieto, R., “Otros poetas griegos próximos a Orfeo”,en A. Bernabé \& F. Casadesús (eds.), Orfeo y la tradición órfica: un reencuentro, Madrid, 2008, 549-576.

McLeod, W. E., "Oral Bards at Delphi”, TAPhA, 92, 1961, 317-325.

Nilsson, M. P., La religion populaire dans la Grèce antique, Paris, 1954.

Parke, H. W., "A note on the Delphic priesthood”, CQ, 34, 1940, 85-89.

—, The Oracles of Apollo in Asia Minor, London, 1985.

Poland, F., "Metragyrtai”, RE XV, 2, Stuttgart, 1932, cols. 1471-1473.

Riedweg, CH., "Orfismo en Empédocles", Taula, 27-28, 1997, 33-59 (= "Orphisches bei Empedokles", $A \mathcal{E} A$, 41, 1995, 34-59).

SANZI, E., I culti orientali nell'impero romano, Cosenza, 2003.

SchröDer, S., Plutarchs Schrift De Pythiae oraculis, Stuttgart, 1990.

Stoessl, F., “Onomakritos”, Der Kleine Pauly 4, München, 1972, cols. 304-305.

West, M. L., The Orphic Poems, Oxford, 1983. 